\title{
Optimization of Multi-Product Aggregate Production Planning using Hybrid Simulated Annealing and Adaptive Genetic Algorithm
}

\author{
Gusti Eka Yuliastuti ${ }^{1}$, Agung Mustika Rizki ${ }^{2}$ \\ Wayan Firdaus Mahmudy ${ }^{3}$ \\ Faculty of Computer Science \\ Brawijaya University, Malang, Indonesia
}

\author{
Ishardita Pambudi Tama ${ }^{4}$ \\ Faculty of Industrial Engineering \\ Brawijaya University, Malang \\ Indonesia
}

\begin{abstract}
In the planning of aggregate production, company stakeholders need a long time due to the many production variables that must be considered so that the production value can meet consumer demand with minimal production costs. The case study is the company that produces more than a type of product so there are several variables must be considered and computational time is required. Genetic Algorithm is applied as they have the advantage of searching in a solution space but are often trapped in locally optimal solutions. In this study, the authors proposed a new mathematical model in the form of a fitness function aimed at assessing the quality of the solution. To overcome this local optimum problem, the authors refined it by combining the Genetic Algorithm and Simulated Annealing so called hybrid approach. The function of Simulated Annealing is to improve every solution produced by Genetic Algorithm. The proposed hybrid method is proven to produce better solutions.
\end{abstract}

Keywords-Agreggate; genetic algorithm; hybrid; production planning; simulated annealing

\section{INTRODUCTION}

The industrial world in Indonesia has experienced tremendous rapid development, especially in manufacturing. This certainly can have an impact on increasing fierce competition between companies. Each company has almost the same goal of wanting to always meet consumer demand. However, the company cannot get rid of one of the problems that must be faced, namely stochastic consumer demand or can be said to be always changing. Every company must be able to overcome these problems so that consumers do not switch to other competing companies. From these basic problems, indirectly every company is required to increase its product production effectively and efficiently to meet consumer demand. Several strategies are usually implemented by the company, among others level strategy, time flexibility strategy and mixed strategy. Each strategy has its advantages and disadvantages so it will be less than optimal in handling stochastic consumer demand problems.

In addition to problems related to consumer demand, some problems are quite crucial for the company that is related to production costs. The problem faced by the company was known after the author interviewed the owner of the company. Every company must be able to optimize all company resources to produce a product that is following consumer demand but with minimal cost. Because the amount of production costs is very influential to the profits of the company, so the calculation of production costs needs to be done optimally. To achieve the goals of the company, of course, there is a need for optimal production planning. By the optimal production planning, it will be able to minimize production costs but still be able to meet consumer demand so that the profits obtained by the company will be maximized. One way to do production planning in the medium term is aggregate planning. Aggregate production planning is a procedure to translate the expected sales demand and also the capacity of product production availability for production plans in the coming period [1].

Based on this background, the author conducts research related to production planning to address the problem of stochastic consumer demand and minimize production costs incurred. This problem is important to solve because it is relate to something crucial in the company. The method that will be applied by the author is the Genetic Algorithm, but solving the problem using the Genetic Algorithm is often a new problem that is the occurrence of early convergence or the solution achieved in several iterations there is no significant increase. Therefore, the author will give a little modification to the Genetic Algorithm and then combine it with the Simulated Annealing method to get more optimal results. The Simulated Annealing method works to improve the solution generated by the Genetic Algorithm after the solution is fixed by Simulated Annealing, the best solution will be returned to the Genetic Algorithm to continue the process until the stop condition is reached. The selection of the Simulated Annealing method by the author is based on previous research by Zhang et al., [2]. Their hybrid is done by entering the process flow of the Simulated Annealing method into the Genetic Algorithm process flow in general. The fundamental difference in this study compared to before is the modification of the process flow of the Genetic Algorithm. By this modification, the aim is that the resulting solution will be more optimal and also the Genetic Algorithm will avoid early convergence.

\section{LITERATURE REVIEW}

Several studies have previously been carried out related to production planning which includes aggregate production, scheduling, distribution and so forth. 
Fahimnia et al., [3] optimize the integration of aggregate production and distribution planning using Genetic Algorithms. This Genetic Algorithm is used to determine the combination of the production of various types of products in several manufacturing plants and also the distribution of finished products from the factory to many users either through direct or indirect transportation routes.

The combination of two methods namely Genetic Algorithm and Taboo Search was carried out by Ramezanian $e t$ al., [4] to solve the problem of aggregate production planning in a two-phase production system. The problem in this research is that the system is multi-period, multi-product and multimachine. They developed the Mixed Integer Linear Programming (MILP) model for aggregate production planning in two general phases. Because these problems are quite complex, they apply Genetic Algorithms and taboo search. Computational results show that by applying both methods, a solution with better quality and more efficient solutions for large scale problems such as this is found.

Genetic Algorithms are also applied by Chistyakova et al., [5] to the decision support system for optimal planning. Genetic Algorithms are considered algorithms that make it possible to use in solving planning problems that can be reconfigured. After testing the system, the results have proven to be more effective with Genetic Algorithms.

Erfanian and Pirayesh [6] also use Mixed Integer Linear Programming (MILP) to integrate the aggregate production planning and maintenance planning. The purpose of aggregate planning is to determine the level of production and inventory to minimize the total cost of production with limited labor and equipment resources. Also, the purpose of maintenance planning is to improve equipment efficiency to meet production requirements. In the proposed model, integrated aggregate production planning and maintenance are developed to determine the optimal production plan and preventive maintenance for each period.

The issue of integration of production and maintenance planning is also a topic of issues raised by Ettaye et al., [7]. They also apply the Genetic Algorithm to solve these problems. Because according to them, planning maintenance activities can hamper manufacturing operations in terms of cost, quality and time. Besides, it is necessary to ensure the availability of production equipment to meet consumer demand. By using Genetic Algorithms, integrated planning is more optimal.

There is another study that takes a situation of the case of production planning at an oil company conducted by Siregar $e t$ al., [8]. Production planning is less effective and efficient because it only relies on demand data from the past period. This has an impact on high-cost losses. Siregar et al., are used the Goal Programming approach to optimize the company's production planning. This method is used to maximize or minimize the resources of several holding companies with an objective function. Goal Programming is a mathematical model that is suitable for solving multi-purpose problems because it uses variable deviation.
Based on several studies that have been done before, it is proven that Genetic Algorithms can overcome optimization problems. So the method that will also be applied by the author is the Genetic Algorithm. But solving the problem using the Genetic Algorithm apart often begin new problems namely the occurrence of early convergence or solutions achieved in several iterations there is no significant increase. Therefore, the author will give a slight modification to the Genetic Algorithm and then combine it with the Simulated Annealing method so that the aim is to get more optimal results. Modifications made by the author are changing the reproductive process both in crosssover and mutation and also genetic parameters that will be made adaptive to adjust the conditions at that time.

\section{AgGregate Production Planning}

Production planning is planning, organizing beforehand about people, materials, machinery and other equipment and capital needed to produce goods or services in a certain period in the future by what is predicted. Aggregates are demand forecasts for various goods combined into homogeneous units. Aggregate production planning relates to the production capacity used to respond to predicted consumer demand [9].

The case study that will be completed in this research is a home textile company that manufactures school uniforms of 18 types of products including superiors and subordinates. In each type of product, there are eight different sizes. To determine the level of production in the coming period is quite difficult because there is more than one type of product and also each product is done by different workers. Besides that, consumer demand for each product is also different and always changing. This is quite difficult for the company to do production on all types of products. They need to consider various parameters and adjust the rules that apply to the company in achieving optimal solutions. The optimal solution the company wants is that consumer demand is fulfilled with minimal production costs. In this study, several production parameters are used as shown in Table I.

TABLE. I. PARAMETERS IN PRODUCTION PROCESS

\begin{tabular}{|l|l|}
\hline Para-meter & Description \\
\hline$n$ & Number of workers \\
\hline$r t$ & Average production amount per worker in a day (regular time) \\
\hline$s t$ & Average production amount per worker in a day (overtime) \\
\hline$j c$ & Average production amount per worker in a day (subcontract) \\
\hline$j o t$ & Working hours in a day (regular time) \\
\hline$m s c$ & Maximum hours of overtime \\
\hline$b r t$ & Maximum number of subcontract worker \\
\hline$b o t$ & Production cost (regular time) \\
\hline$b s c$ & Production cost (overtime) \\
\hline$r p$ & Production cost (subcontract) \\
\hline$p r p$ & Number of worker recruited (hiring) \\
\hline$b r p$ & Average amount of production per new worker in a day \\
\hline$m p$ & Cost of recruiting worker \\
\hline$b m p$ & Number of laid-off worker \\
\hline$k p$ & Cost of laying off worker (firing) \\
\hline$i$ & Number of production shortages \\
\hline$b i$ & Number of inventory product \\
\hline
\end{tabular}




\section{ModifIEd GeNETIC ALGORITHM}

Genetic Algorithm is a method adapted from the natural evolutionary process [10]. The terms in the Genetic Algorithm also use terms that are commonly used in the evolutionary process including genes, chromosomes, individuals, populations, generations, and reproduction. Genes are the smallest parts that represent solution units. Chromosomes are a collection of genes if assembled will be a solution. Such chromosome lines are also referred to as individuals. A collection of individuals is called a population. Whereas generation is a time when the population is still alive and the generation will continue to move forward with a population that will always change. Reproduction is the process of producing new individuals.

\section{A. Chromosome Representation}

The type of chromosome encoding used to represent the solution is real-coded. If there is a fractional value, then the value will be rounded when calculating the fitness value. Rounding the value in a way if the value is more than half it will be rounded up and vice versa. In a series of chromosomes, there are 18 segments that indicate the number of products. In each segment, there are 12 genes indicating the number of periods counted (for 12 months). The total length of the chromosome is 216 genes.

\section{B. Reproduction Operator}

Reproduction operators are needed to produce new individuals. There are two reproduction operators, crossover and mutation [11]. The difference between these operators is in the number of parent chromosomes used. In the crossover process, requires 2 parent chromosome, whereas in mutation only need 1 parent chromosome. The two operators are used at the same time but the rate should be determined at the beginning. For example, the crossover rate $(c r)$ is set at 0,6 while the mutation rate $(m r)$ is set at 0,4 . Based on those rates, we can conclude that the reproduction process focuses more on the crossover.

1) Crossover process: The crossover method used onecut-point-crossover in each segment to aim that the individual produced is more varied. Then generate a random value in each segment between intervals [1] because there are 12 genes in each segment indicates 12 months. The random value will be used as a reference gene that becomes the point of intersection. For example, on the parent chromosome, there are 12 genes with 3 segments as shown in Fig. 1.

In segment 1 , we generate a random value and get a value that is 2. It means the second gene is cut as shown in Fig. 2.

In segment 2 , we generate a random value and get a value that is 3 . It means the third gene is cut as shown in Fig. 3.

In segment 3 , we generate a random value and get a value that is 1 . It means the first gene is cut as shown in Fig. 4.

Based on the crossover process, it produces the following child chromosome as shown in Fig. 5.

\begin{tabular}{|c|c|c|c|c|c|c|c|c|c|c|c|}
\hline \multicolumn{4}{|c|}{ Segment 1} & \multicolumn{4}{|c|}{ Segment 2} & \multicolumn{4}{|c|}{ Segment 3} \\
\hline$\Gamma$ & & & 1 & $\Gamma$ & & & | & $\Gamma$ & & & \\
\hline $\begin{array}{c}22, \\
1 \\
\end{array}$ & $\begin{array}{c}10 \\
9\end{array}$ & 5,0 & 32,5 & 27,8 & 4,3 & 17,2 & 3,2 & 19,0 & 9,4 & 10,5 & 11,8 \\
\hline $\begin{array}{c}14, \\
0\end{array}$ & $\begin{array}{c}21, \\
8\end{array}$ & 3,7 & 13,5 & 14,4 & 7,9 & 23,4 & 9,5 & 21,5 & 4,6 & 13,7 & 12,2 \\
\hline
\end{tabular}

Fig. 1. Illustration of Chromosome Representation for Crossover.

\begin{tabular}{|l|l|l|l|l|l|l|l|l|l|}
\hline 22,1 & 10,9 & 5,0 & 32,5 & $\mathrm{P} 1$ & $\mathrm{C} 1$ & 22,1 & 10,9 & 3,7 & 13,5 \\
\hline 14,0 & 21,8 & 3,7 & 13,5 & $\mathrm{P} 2$
\end{tabular}$\quad$\begin{tabular}{rl|l|l|l|}
14,0 & 21,8 & 5,0 & 32,5 \\
\hline
\end{tabular}

Fig. 2. Illustration of Crossover in Segment 1.

\begin{tabular}{|c|c|c|c|c|c|c|c|c|c|}
\hline 27,8 & 4,3 & 17,2 & 3,2 & P1 & $\mathrm{C} 1$ & 27,8 & 4,3 & 17,2 & 9,5 \\
\hline 14,4 & 7,9 & 23,4 & 9,5 & P2 & $\mathrm{C} 2$ & 14,4 & 7,9 & 23,4 & 3,2 \\
\hline
\end{tabular}

Fig. 3. Illustration of Crossover in Segment 2.

\begin{tabular}{|l|l|l|l|l|l|l|l|l|l|}
\hline 19,0 & 9,4 & 10,5 & 11,8 & $\mathrm{P} 1$ & $\mathrm{C} 1$ & 19,0 & 4,6 & 13,7 & 12,2 \\
\hline 21,5 & 4,6 & 13,7 & 12,2 & $\mathrm{P} 2$ & $\mathrm{C} 2$ & \begin{tabular}{|l|l|l|l|}
21,5 & 9,4 & 10,5 & 11,8 \\
\hline
\end{tabular}
\end{tabular}

Fig. 4. Illustration of Crossover in Segment 3.

\begin{tabular}{|}
\begin{tabular}{|c|c|c|c|c|c|c|c|c|c|c|c|}
\hline $\begin{array}{c}22, \\
1\end{array}$ & $\begin{array}{c}10, \\
9\end{array}$ & 3,7 & 13,5 & 27,8 & 4,3 & 17,2 & 9,5 & 19,0 & 4,6 & 13,7 & 12,2 \\
\hline \begin{tabular}{c}
\hline $\begin{array}{c}14, \\
0\end{array}$ \\
$\begin{array}{c}21, \\
8\end{array}$
\end{tabular} & 5,0 & 32,5 & 14,4 & 7,9 & 23,4 & 3,2 & 21,5 & 9,4 & 10,5 & 11,8 \\
\hline
\end{tabular}
\end{tabular}

Fig. 5. Illustration of Child Chromosome Result.

2) Mutation process: The mutation method used positionbased-mutation in each segment to minimize the occurrence of early convergence. Then generate a random value in each segment between intervals [1] because there are 12 genes in each segment indicates 12 months. The random value will be used to determine the position of the point whose value will be changed. The value at that position will be changed by generating a random value with a range of \pm 10 from the initial value. For Example, on the parent chromosome, there are 12 genes with 3 segments as shown in Fig. 6 .

In segment 1 , we generate a random value and get a value that is 1 . It means the first gene has to be changed. The new value is obtained by another random value and get a value that is 27,4 as shown in Fig. 7.

In segment 2, we generate a random value and get a value that is 4 . It means the fourth gene has to be changed. The new value is obtained by another random value and get a value that is 12,5 as shown in Fig. 8.

In segment 3, we generate a random value and get a value that is 3 . It means the third gene has to be changed. The new value is obtained by another random value and get a value that is 17,3 as shown in Fig. 9.

Based on the mutation process, it produces the following child chromosome as shown in Fig. 10. 


\begin{tabular}{|c|c|c|c|c|c|c|c|c|c|c|}
\hline \multicolumn{4}{|c|}{ Segment 1} & \multicolumn{4}{|c|}{ Segment 2} & \multicolumn{3}{|c|}{ Segment 3} \\
\hline 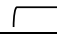 & & & 1 & & & & & & & \\
\hline 22, & $\begin{array}{c}10, \\
9\end{array}$ & 5,0 & 32,5 & 27,8 & 4,3 & 17,2 & 3,2 & 19, & & 11,8 \\
\hline
\end{tabular}

Fig. 6. Illustration of Chromosome Representation for Mutation

\begin{tabular}{l|l|l|l}
27,4 & 10,9 & 5,0 & 32,5 \\
\hline
\end{tabular}

Fig. 7. Illustration of Mutation in Segment 1.

\begin{tabular}{|l|l|l|l|}
\hline 27,8 & 4,3 & 17,2 & 12,5 \\
\hline
\end{tabular}

Fig. 8. Illustration of Mutation in Segment 2.

\begin{tabular}{|l|l|l|l|}
\hline 19,0 & 9,4 & 17,3 & 11,8 \\
\hline
\end{tabular}

Fig. 9. Illustration of Mutation in Segment 3.

\begin{tabular}{|c|c|c|c|c|c|c|c|c|c|c|c|}
\hline $\begin{array}{c}22, \\
1\end{array}$ & $\begin{array}{c}10, \\
9\end{array}$ & 3,7 & 13,5 & 27,8 & 4,3 & 17,2 & 9,5 & 19,0 & 4,6 & 13,7 & 12,2 \\
\hline \begin{tabular}{c|c|c|c|c|c|c|c|c|}
\hline $\begin{array}{c}14, \\
0\end{array}$ \\
\hline
\end{tabular} & $\begin{array}{c}21, \\
8\end{array}$ & 5,0 & 32,5 & 14,4 & 7,9 & 23,4 & 3,2 & 21,5 & 9,4 & 10,5 & 11,8 \\
\hline
\end{tabular}

Fig. 10. Illustration of Child Chromosome Result.

\section{Selection Operator}

The type of selection operator used is elitism for reasons that are not complex so it does not take a long time at the time of execution. In conducting individual selection, it is necessary to have a unit of value to compare or hereinafter referred to as fitness value. This fitness value does not have a patent formula because it will never be the same because the formula is structured to solve the problem at hand. The fitness value formulation for this problem is shown as (2).

Total of Production Cost

$=\left(\sum r t . b r t\right)+\left(\sum o t . b o t\right)+\left(\sum s c . b s c\right)+\left(\sum r p . b r p\right)$

$+\left(\sum m p . b m p\right)+\left(\sum i . b i\right)$

Fitness Value $=\frac{100000000}{\text { Total Production Cost }+ \text { Penalty }}$

A penalty is some conditions that can reduce the quality of a solution such as inventory value minus. It means the company cannot complete consumer demand. If some rules are not suitable for the company related to the number of workers, the time of workers and so on, it can count as a penalty.

\section{Adaptive Parameter}

The adaptive parameter in the Genetic Algorithm referred to the value of the crossover and mutation rates which can adapt depending on the situation and conditions that occur at that time. The value will change and be randomized if in 10 iterations there are no better results.

\section{E. Hybrid with Simulated Annealing}

The Simulated Annealing (SA) and Genetic Algorithm (GA) certainly have their respective weaknesses. This research will combine the two algorithms with the hope that they will get more optimal results. The hybrid process of Simulated Annealing Algorithm and Genetic Algorithm (HSAGA) consists of combining the Genetic Algorithm with Simulated Annealing Algorithm iteratively [2]. The difference between this study and previous research is the modification of AG using adaptive parameters which are then proposed to be the method of Hybrid Simulated Annealing and Adaptive Genetic Algorithm (HSAAGA). At HSAAGA, SA is considered as an operator in AGA that functions to manage the population optimally [12]. During the initial AGA process, genetic operators are used as usual to produce new individuals and then SA operators are used to identifying these individuals.

\section{RESUlt AND ANALYSIS}

The testing results of the proposed method namely Hybrid of Simulated Annealing - Adaptive Genetic Algorithm (HSAAGA) as shown in Table II. In the previous trial, all the best parameters were obtained from each method. All the best parameters will be used by the author to test the HSAAGA method. The best parameters in the Adaptive Genetic Algorithm are population size $=70$, number of generations $=$ 1000 , combination of $\mathrm{cr}=0.5$ and $\mathrm{mr}=0.5$. As for the best parameters on Simulated Annealing namely the number of new solutions generated as many as 9 , temperature $=175$, reduction factor $=0.5$ and maximum iteration $=100$.

From 10 trials, an average fitness value of 0.4480 was obtained. The best solution with the highest fitness value is 0.4713 with execution time during $19701866 \mathrm{~ms}$.

Knowing that this proposed method is the best method in solving the problem of aggregate production planning with optimal results, it needs to be proven by comparing it with other methods as shown in Table III. Each method will be run 5 times with the same time limit i.e. during 120 minutes so that the resulting solution is fairer in the comparative test of this method.

TABLE. II. ThE TESTING RESUlTs of HSAAGA

\begin{tabular}{|c|c|c|c|c|c|c|c|c|c|c|c|}
\hline & \multicolumn{10}{|c|}{ Trials } & \multirow{2}{*}{$\begin{array}{l}\text { Averag } \\
\text { e }\end{array}$} \\
\hline & 1 & 2 & 3 & 4 & 5 & 6 & 7 & 8 & 9 & 10 & \\
\hline 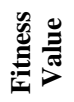 & $\underset{0}{\stackrel{m}{+}}$ & $\frac{8}{\dot{f}}$ & ङे & \begin{tabular}{l} 
ते \\
$\stackrel{3}{*}$ \\
\multirow{2}{*}{}
\end{tabular} & 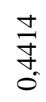 & $\stackrel{\substack{\infty \\
+\infty}}{\dot{\infty}}$ & $\begin{array}{l}\infty \\
\stackrel{0}{f} \\
\dot{f}\end{array}$ & 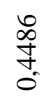 & 字 & 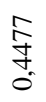 & 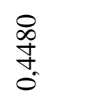 \\
\hline 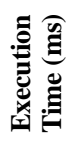 & 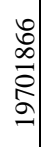 & $\begin{array}{l}\hat{\infty} \\
n \\
2 \\
2 \\
\sigma\end{array}$ & $\frac{\sqrt[n]{J}}{\stackrel{\Xi}{\Xi}}$ & 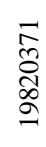 & 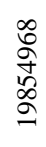 & 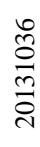 & $\begin{array}{l}n \\
\sqrt[n]{\delta} \\
+ \\
\infty \\
0\end{array}$ & 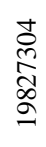 & 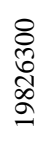 & $\begin{array}{l}0 \\
2 \\
2 \\
\hat{2} \\
\vdots\end{array}$ & 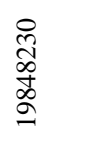 \\
\hline
\end{tabular}

TABLE. III. METHODS COMPARATION

\begin{tabular}{|c|c|c|c|c|c|c|}
\hline \multirow{3}{*}{ 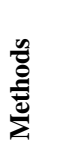 } & \multicolumn{6}{|c|}{ Fitness Value } \\
\hline & \multicolumn{5}{|l|}{ Trials } & \multirow{2}{*}{ Average } \\
\hline & 1 & 2 & 3 & 4 & 5 & \\
\hline SA & 0,22845 & 0,25940 & 0,23383 & 0,21125 & 0,22366 & 0,231321 \\
\hline GA & 0,29984 & 0,30854 & 0,28576 & 0,31006 & 0,27509 & 0,295862 \\
\hline AGA & 0,32141 & 0,32881 & 0,32942 & 0,34106 & 0,33106 & 0,330356 \\
\hline $\begin{array}{l}\text { HSA- } \\
\text { AGA }\end{array}$ & 0,47132 & 0,44907 & 0,44395 & 0,43202 & 0,44145 & 0,447567 \\
\hline
\end{tabular}


The proposed method of HSAAGA produces the highest average fitness value. Adaptive Genetic Algorithm that improved using Simulated Annealing was quite effective as evidenced by the increase in fitness value. The existence of adaptive parameters value of $c r$ and $m r$ in the Genetic Algorithm is very important in increasing yield. In addition, modifications during the reproduction process also play an important role in expanding the search space for solutions so that it is likely to achieve optimal solutions.

The actual aggregate production planning for the first product carried out by the company requires a production cost of Rp. 645,703,000. Different results are obtained by applying the HSAAGA method to carry out aggregate production planning for the first product.

The total production costs to be incurred by the company if applying the HSAAGA method is Rp. 612,731,500. There is a difference in the production costs of Rp. 32,971,500, - in the production of the first product which is quite influential for the company because the products produced by the company are quite a lot, namely 18 products. By applying this proposed method HSAAGA, the company can carry out aggregate production planning to get optimal results effectively and efficiently.

After obtaining the final solution in the form of the amount of production from the application of the method then the writer compares with consumer demand to see the difference as shown in Fig. 11.

\section{CONCLUSION}

Aggregate production planning using the proposed method can produce an optimal solution because in determining the quality of a solution considered the total production costs incurred, the total number of workers, the total cost for workers and also some penalties that are not in accordance with company rules. So that, the final solution achieved represents the total minimum production costs and minimum penalties by hiring workers as needed for the production process, this can certainly have a good impact on the profits of the company.

The hybrid carried out between Simulated Annealing and the Adaptive Genetic Algorithm produced the most optimal solution. The purpose of this hybrid, the authors want to further increase the exploitation of the quality of the solutions that have been produced. Simulated Annealing functions to improve the solutions produced by Adaptive Genetic Algorithms. Every improvement can certainly improve the quality of the resulting solution so that the solution is considered more optimal. The most optimal solution resulting from the hybrid of Simulated Annealing and Adaptive Genetic Algorithm to carry out multi-product aggregate production planning is the fitness value of 0.4713223 with a production cost of Rp. 2,176,631,500.

For future work, this hybrid method can be used for another case study. On the other hand, another heuristic method can be added to increase the solution from this hybrid method.

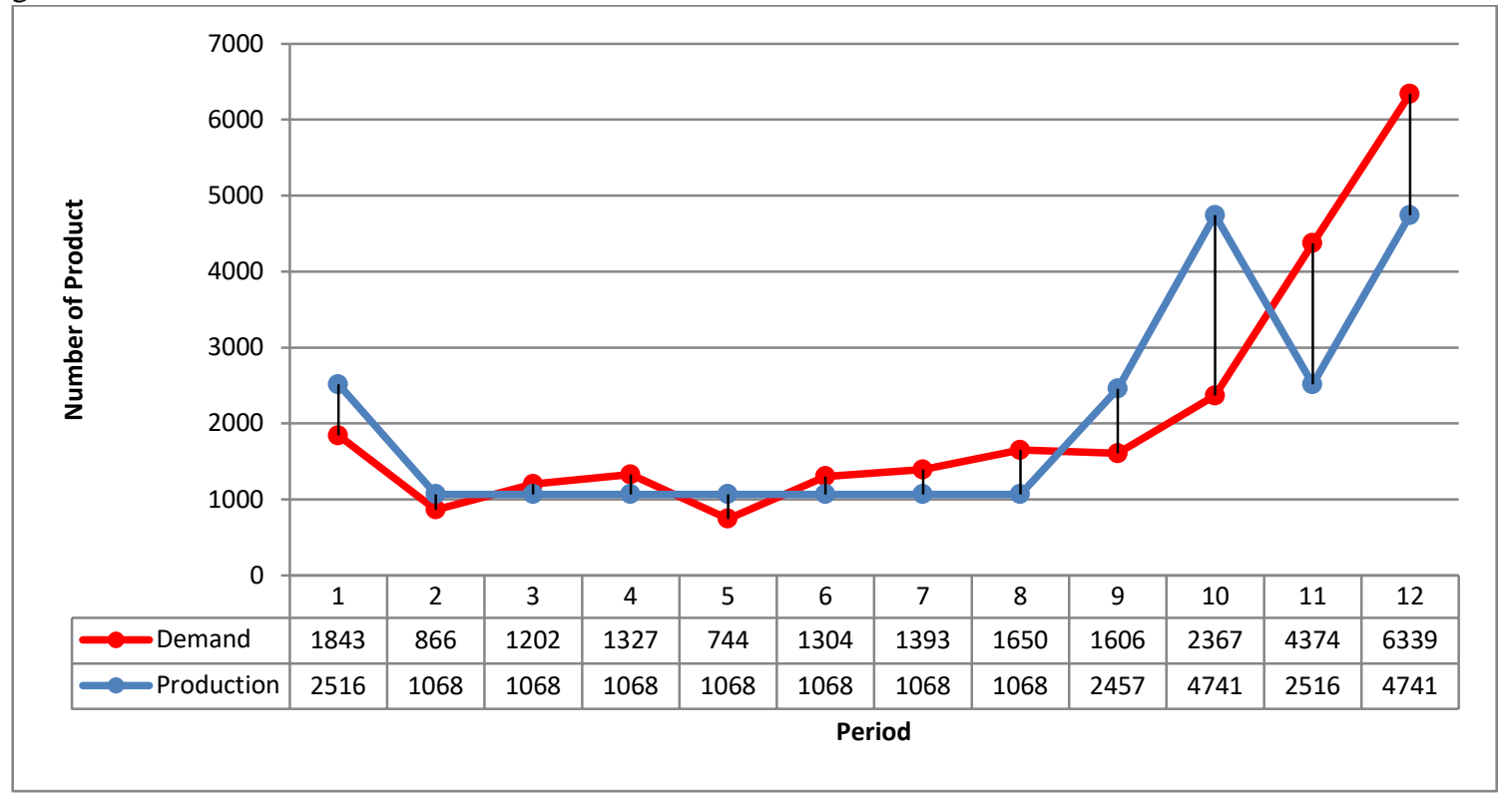

Fig. 11. Comparison of Demand and Production. 


\section{REFERENCES}

[1] M. Kumar and A. N. Haq, "Hybrid Genetic - Ant Colony Algorithms for Solving Aggregate Production Plan," vol. 4, no. 1, pp. 103-111, 2005.

[2] Y. Zhang, Q. Huang, F. Gao, and X. Sun, “Optimal Reservoir Operation Using a Hybrid Simulated Annealing Algorithm-Genetic Algorithm," Bio-Inspired Comput. Theor. Appl., 2010.

[3] B. Fahimnia, L. Luong, and R. Marian, "Genetic Algorithm Optimisation of An Integrated Aggregate Production - Distribution Plan in Supply Chains,” Int. J. Prod. Res., no. October 2013, pp. 37-41, 2012.

[4] R. Ramezanian, D. Rahmani, and F. Barzinpour, "An Aggregate Production Planning Model for Two Phase Production Systems: Solving with Genetic Algorithm and Tabu Search," Expert Syst. Appl., vol. 39, pp. 1256-1263, 2012.

[5] T. B. Chistyakova, A. S. Razygrayev, and R. V Makaruk, "Decision Support System for Optimal Production Planning Polymeric Materials Using Genetic Algorithms," in Soft Computing and Measurements (SCM), 2016, pp. 257-259.

[6] M. Erfanian and M. Pirayesh, "Integration Aggregate Production Planning and Maintenance Using Mixed Integer Linear Programming," IEEE Int. Conf. Ind. Eng. Eng. Manag., vol. 2016-Decem, pp. 927-930, 2016.
[7] G. Ettaye, A. E. L. Barkany, and A. E. L. Khalfi, “Applying Genetic Algorithm for Integrated Planning of Production and Maintenance," in Logistics and Supply Chain Management (LOGISTIQUA), 2017, pp. 166-170.

[8] I. Siregar, U. Tarigan, D. A. Siregar, R. M. Sari, M. M. Tambunan, and T. H. Nasution, "Determination of Optimal Production Planning in Palm Oil Company (Case Study)," in International Conference on Industrial Engineering and Applications, 2017.

[9] J. Heizer and B. Render, Production and Operations Management Strategies and Tactics. New Jersey: Prentice Hall, 1993.

[10] W. F. Mahmudy, R. M. Mariana, and L. H. S. Luong, "Hybrid Genetic Algorithms for Multi-period Part Type Selection and Machine Loading Problems in Flexible Manufacturing System," in IEEE International Conference on Computational Intelligence and Cybernetics (CYBERNETICSCOM), 2013.

[11] V. N. Wijayaningrum and W. F. Mahmudy, "Optimization of Ship's Route Scheduling Using Genetic Algorithm,' Indones. J. Electr. Eng. Comput. Sci., vol. 2, no. April, pp. 180-186, 2016.

[12] G. E. Yuliastuti, A. M. Rizki, W. F. Mahmudy, and I. P. Tama, "Determining Optimum Production Quantity on Multi- Product Home Textile Industry by Simulated Annealing," J. Inf. Technol. Comput. Sci., vol. 1 , no. $1,2018$. 